\title{
Syntheses, magnetic and spectral studies on polystyrene supported coordination compounds of bidentate and tetradentate Schiff bases
}

\author{
D KUMAR*, P K GUPTA and A SYAMAL ${ }^{\dagger}$ \\ Department of Chemistry, National Institute of Technology, Kurukshetra 136 119, India \\ ${ }^{\dagger}$ Present address: D708, Ushanagar, Bhandup, Mumbai 400 078, India \\ e-mail: dkumar_nitk@yahoo.com
}

MS received 24 May 2004; revised 6 December 2004

\begin{abstract}
The reaction of aminomethylated polystyrene $\left(\mathrm{PSCH}_{2}-\mathrm{NH}_{2}\right)$ and 2-hydroxyacetanilide in DMF results in the formation of polystyrene-anchored monobasic bidentate Schiff base, $\mathrm{PSCH}_{2}-\mathrm{LH}_{(\mathbf{I}) \text {. }}$ On the other hand, the reaction of chloromethylated polystyrene $\left(\mathrm{PSCH}_{2}-\mathrm{Cl}\right)$, 3-formylsalicylic acid, ethylenediamine and acetylacetone in DMF in presence of ethyl acetate (EA) and triethylamine (TEA) produces another polystyrene-anchored dibasic tetradentate Schiff base, $\mathrm{PSCH}_{2}-\mathrm{L}^{\prime} \mathrm{H}_{2}$ (II). Both I and II react with a number of di-, tri- and hexavalent metal ions like $\mathrm{Co}, \mathrm{Ni}, \mathrm{Cu}, \mathrm{Zn}$ and $\mathrm{Cd}$ to form polystyreneanchored coordination compounds, and these have been characterized and discussed.
\end{abstract}

Keywords. Polystyrene-anchored Schiff bases; coordination compounds; magnetic susceptibility measurements; basicity and denticity.

\section{Introduction}

Reaction of polymer-anchored ligands with metal ions provide an easy route for the synthesis of immobilized transition metal compounds. ${ }^{1}$ Structural studies of polymer-supported compounds appear to be useful and interesting in view of their numerous applications such as in organic synthesis, ${ }^{2}$ immobilization of enzymes, ${ }^{3}$ biological systems, ${ }^{4}$ dyes, ${ }^{5}$ analytical chemistry, ${ }^{6}$ catalysis, ${ }^{7}$ substrate carriers, ${ }^{8}$ protecting groups ${ }^{9}$ and heavy metal ions uptake ${ }^{10}$ etc. Schiff bases are the most versatile and thoroughly studied ligands in coordination chemistry. On account of their pronounced coordinating properties, a number of tridentate ${ }^{11}$ Schiff bases have been anchored to the polystyrene matrix; however, relatively less work has been done on bidentate ${ }^{12}$ and tetradentate ${ }^{13}$ Schiff bases. We describe here the syntheses and characterization of polystyrene-anchored coordination compounds of $\mathrm{PSCH}_{2}-\mathrm{LH}$ (I) and $\mathrm{PSCH}_{2}-\mathrm{L}^{\prime} \mathrm{H}_{2}$ (II) with $\mathrm{MoO}_{2}(\mathrm{VI}), \mathrm{Co}(\mathrm{II}), \mathrm{Cu}(\mathrm{II})$, $\mathrm{Zn}(\mathrm{II}), \mathrm{Cd}(\mathrm{II}), \mathrm{Ni}(\mathrm{II}), \mathrm{Fe}(\mathrm{III}), \mathrm{Zr}(\mathrm{IV})$ and $\mathrm{UO}_{2}(\mathrm{VI})$ ions. It is expected that the present compounds may find use in several fields.

\footnotetext{
*For correspondence
}<smiles>CC(=NCc1ccccc1)Nc1ccccc1O</smiles>

(I)<smiles>CC1=CC(C)=NCCN=Cc2cccc(C(=O)OCc3ccccc3)c2O1</smiles>

(II)

\section{Experimental}

Aminomethylated polystyrene (containing $3 \mathrm{mmol}$ of $\mathrm{NH}_{2}$ per gram of resin) and $1 \%$ crosslinked with divinylbenzene, chloromethylated polystyrene (containing $0.94 \mathrm{mmol}$ of $\mathrm{Cl}$ per gram of resin and $1 \%$ crosslinked with divinylbenzene) (Sigma, USA), iron(III) chloride (anhydrous), cobalt(II) acetate tetrahydrate, cadmium(II) acetate tetrahydrate, dioxouranium(VI) acetate tetrahydrate, hexadecaaquaoctahydroxotetrazirconium(IV) chloride [BDH]; nickel(II) acetate tetrahydrate [Fluka AG (Switzer- 
land)], zinc(II) acetate dihydrate (SD's Fine Chemicals), copper(II) acetate monohydrate, petroleum ether (boiling range: $60-80^{\circ} \mathrm{C}$ ) [IDPL], 2-hydroxyacetanilide (Aldrich, USA), manganese(II) acetate tetrahydrate, acetylacetone, ethylenediamine (Sarabhai, India); dimethylformamide, methanol, and acetone (Ranbaxy, India) were used for the syntheses. Bis (acetylacetonato)dioxomolybdenum(VI), 3-formylsalicyclic acid and hexadecaaquatetrazirconium(IV) acetate were prepared by adopting published procedures. ${ }^{14}$ Analysis of the metal contents, coordinated DMF, IR, reflectance, ESR spectral studies and magnetic susceptibility measurements on the polystyrene-anchored coordination compounds were carried out as mentioned in our earlier publication. ${ }^{14}$

\subsection{Synthesis of $\mathrm{PSCH}_{2}-\mathrm{LH}(\mathbf{I})$}

$\mathrm{PSCH}_{2}-\mathrm{NH}_{2}(1.0 \mathrm{~g})$ was allowed to swell in DMF $(20 \mathrm{ml})$ for $45 \mathrm{~min}$. A DMF solution $(50 \mathrm{ml})$ of 2hydroxyacetanilide $(1.36 \mathrm{~g}, 9 \mathrm{mmol})$ was added to the above suspension. The mixture was heated under reflux for $8 \mathrm{~h}$, while stirring magnetically. The cream-coloured product obtained was cooled to room temperature and then was suction-filtered, washed several times with DMF, $\mathrm{CH}_{3} \mathrm{OH}, \mathrm{C}_{2} \mathrm{H}_{5} \mathrm{OH}$ and petroleum ether and finally dried in vacuo at room temperature.

\subsection{Synthesis of $N, N^{\prime}$-ethylenemono(acetylaceto- neimine)mono(3-carboxysalicylideneimine), $L^{\prime} H_{3}$}

An ethanolic solution $(30 \mathrm{ml})$ of 3-formylsalicyclic acid $(1.66 \mathrm{~g}, 10 \mathrm{mmol})$ was mixed with an ethanolic solution $(15 \mathrm{ml})$ of acetylacetone $(1.0 \mathrm{~g}, 10 \mathrm{mmol})$. The mixture was kept in an ice bath for $1 / 2 \mathrm{~h}$. An ethanolic solution of ethylenediamine $(0.60 \mathrm{~g}$, $10 \mathrm{mmol}$ ) was added slowly to the above mixture with constant stirring. The mixture was heated under reflux for $45 \mathrm{~min}$ and the yellow-coloured product separated during refluxion was brought to room temperature. The compound was suction-filtered, washed with and recrystallized from ethanol and then dried as mentioned above. Yield: $80 \%$ (m.p. $\left.285^{\circ} \mathrm{C}\right)$.

\subsection{Synthesis of $\mathrm{PSCH}_{2}-\mathrm{L}^{\prime} \mathrm{H}_{2}(\boldsymbol{I I})$}

$\mathrm{PSCH}_{2}-\mathrm{Cl}(1.0 \mathrm{~g})$ was suspended in DMF $(20 \mathrm{ml})$ for $45 \mathrm{~min}$. A DMF solution $(40 \mathrm{ml})$ of $\mathrm{L}^{\prime} \mathrm{H}_{3}(0.82 \mathrm{~g}$,
$2.82 \mathrm{mmol}$ ) was added to the above suspension. The mixture was heated under reflux for $8 \mathrm{~h}$, while stirring magnetically in presence of ethyl acetate $(100 \mathrm{ml})$ and triethylamine $(2 \mathrm{ml})$. The mixture was cooled to room temperature and the yellow coloured product obtained was suction-filtered, washed thoroughly with DMF, ethyl acetate, ethanol, methanol and petroleum ether, and finally dried as mentioned above.

\subsection{Syntheses of $\mathrm{PSCH}_{2}-\mathrm{LM}\left(\mathrm{CH}_{3} \mathrm{COO}\right) \cdot \mathrm{DMF}$ (where $\mathrm{M}=\mathrm{Cu}, \mathrm{Zn}, \mathrm{Cd}, \mathrm{UO}_{2}$ ), $\mathrm{PSCH}_{2}-\mathrm{LNi}$ $\left(\mathrm{CH}_{2} \mathrm{COO}\right) \cdot 3 \mathrm{DMF}, \mathrm{PSCH}_{2}-\mathrm{L}^{\prime} \mathrm{M}(\mathrm{M}=\mathrm{Ni}, \mathrm{Cu}, \mathrm{Zn}$, $\mathrm{Cd}, \mathrm{UO}_{2}$ ) and $\mathrm{PSCH}_{2}-L^{\prime} \mathrm{Mn} \cdot 2 \mathrm{DMF}$}

$\mathrm{PSCH}_{2}-\mathrm{LH}$ (I) $(1.0 \mathrm{~g}, 3 \mathrm{mmol})$ or $\mathrm{PSCH}_{2}-\mathrm{L}^{\prime} \mathrm{H}_{2}$ (II) $(1.0 \mathrm{~g}, 0.94 \mathrm{mmol})$ was allowed to swell in DMF $(20 \mathrm{ml})$ for $1 \mathrm{~h}$. A hot DMF solution $(40-50 \mathrm{ml})$ of appropriate metal acetate $(6 \mathrm{mmol}$ in case of $\mathbf{I}$ or $1.88 \mathrm{mmol}$ in case of $\mathbf{I I}$ ) was added to the above swollen suspension. The mixture was heated under reflux for $8 \mathrm{~h}$, while stirring magnetically and then cooled to room temperature. The coloured products obtained were suction-filtered, washed with DMF, methanol, ethanol and acetone, and dried as mentioned above.

\subsection{Synthesis of $\mathrm{PSCH}_{2}-\mathrm{LCO}\left(\mathrm{CH}_{3} \mathrm{COO}\right) \cdot \mathrm{DMF}$ and $\mathrm{PSCH}_{2}-\mathrm{L}^{\prime} \mathrm{Co}$}

$\mathrm{PSCH}_{2}-\mathrm{LH}$ (I) $(1.0 \mathrm{~g}, 3 \mathrm{mmol})$ or $\mathrm{PSCH}_{2}-\mathrm{L}^{\prime} \mathrm{H}_{2}$ (II) $(1.0 \mathrm{~g}, 0.94 \mathrm{mmol})$ was allowed to swell in DMF (20 ml) for $1 \mathrm{~h}$ and $\mathrm{N}_{2}$ gas was passed through it for $1 / 2 \mathrm{~h}$. A hot DMF solution $(40 \mathrm{ml})$ of cobalt(II) acetate tetrahydrate $(6 \mathrm{mmol}$ in case of $\mathbf{I}$ or $1.88 \mathrm{mmol}$ in case of II) (flushed with $\mathrm{N}_{2}$ ) was added to the above swollen suspension. The mixture was heated under reflux for $8 \mathrm{~h}$ in $\mathrm{N}_{2}$ atmosphere, while stirring magnetically under anhydrous conditions. The light-brown or brown-coloured products obtained were suctionfiltered, washed with DMF, absolute ethanol, methanol, and acetone, and dried as mentioned above.

\subsection{Synthesis of $\mathrm{PSCH}_{2}-\mathrm{LFeCl}_{2} \cdot 2 \mathrm{DMF}$ and $\mathrm{PSCH}_{2}-\mathrm{L}^{\prime} \mathrm{FeCl} \cdot \mathrm{DMF}$}

$\mathrm{PSCH}_{2}-\mathrm{LH}$ (I) $(1.0 \mathrm{~g}, 3 \mathrm{mmol})$ or $\mathrm{PSCH}_{2}-\mathrm{L}^{\prime} \mathrm{H}_{2}$ (II) $(1.0 \mathrm{~g}, 0.94 \mathrm{mmol})$ was allowed to swell in DMF $(20 \mathrm{ml})$ for $1 \mathrm{~h}$. A hot DMF solution $(40 \mathrm{ml})$ of iron(III) chloride (anhydrous) (6 $\mathrm{mmol}$ in case of $\mathbf{I}$ 
<smiles>CC(=O)Nc1ccccc1O</smiles><smiles>CC(=NCCN=Cc1cccc(C(=O)O)c1O)C(C)=C(C)C(F)(F)F</smiles>

Scheme 1. $\mathrm{EA}=$ ethyl acetate and TEA = triethylamine.

or $1.88 \mathrm{mmol}$ in case of case II) was added to the above swollen suspension. The mixture was heated under reflux for $8 \mathrm{~h}$, while stirring magnetically. The brown or reddish-brown coloured products obtained were cooled to room temperature and then were suction-filtered, washed several times with DMF, methanol, ethanol and acetone. The products were dried as mentioned above.

\subsection{Synthesis of $\mathrm{PSCH}_{2}-\mathrm{LMoO}_{2}$ (acac) and $\mathrm{PSCH}_{2}-\mathrm{L}^{\prime} \mathrm{MoO}_{2}$}

$\mathrm{PSCH}_{2}-\mathrm{LH}$ (I) $(1.0 \mathrm{~g}, 3 \mathrm{mmol})$ or $\mathrm{PSCH}_{2}-\mathrm{L}^{\prime} \mathrm{H}_{2}$ (II) $(1.0 \mathrm{~g}, 0.94 \mathrm{mmol})$ was allowed to swell in DMF $(20 \mathrm{ml})$ for $1 \mathrm{~h}$. A hot DMF solution $(50 \mathrm{ml})$ of bis (acetylacetonato)dioxomolybedenum(VI) $\quad(6 \mathrm{mmol}$ in case of $\mathbf{I}$ or $1.88 \mathrm{mmol}$ in case of $\mathbf{I I}$ ) was added to the above swollen suspension. The mixture was heated under reflux for $8 \mathrm{~h}$, while stirring magnetically. The yellow or yellowish-brown coloured products obtained were cooled to room temperature and then were suction-filtered, washed several times with DMF, methanol, ethanol and acetone. The products were dried as mentioned above.

\subsection{Synthesis of $\mathrm{PSCH}_{2}-\mathrm{L}^{\prime} \mathrm{Zr}(\mathrm{OH})_{2} \cdot \mathrm{DMF}$}

$\mathrm{PSCH}_{2}-\mathrm{L}^{\prime} \mathrm{H}_{2}$ (II) $(1.0 \mathrm{~g}, 0.94 \mathrm{mmol})$ was allowed to swell in DMF $(20 \mathrm{ml})$ for $1 \mathrm{~h}$. A freshly prepared DMF solution $(40 \mathrm{ml})$ of hexadecaaquaoctahydroxotetrazirconium(IV) acetate $(1.88 \mathrm{mmol})$ was added to the above swollen suspension. The mixture was refluxed for $8 \mathrm{~h}$, while stirring magnetically and then cooled to room temperature. The cream-coloured product obtained was suction-filtered, washed with DMF, ethanol, methanol and acetone. The product was dried as mentioned above.

\section{Results and discussion}

The polystyrene-supported Schiff base, $\mathrm{PSCH}_{2}-\mathrm{LH}$ (I) was synthesized by the reaction of 2-hydroxyacetanilide and aminomethylated polystyrene $\left(\mathrm{PSCH}_{2}-\mathrm{NH}_{2}\right.$ ) (containing $3 \mathrm{mmol}$ of $\mathrm{NH}_{2}$ per gram of resin) in DMF. On the other hand, $\mathrm{PSCH}_{2}-\mathrm{L}^{\prime} \mathrm{H}_{2}$ (II) was synthesized by the reaction of chloromethylated polystyrene $\left(\mathrm{PSCH}_{2}-\mathrm{Cl}\right.$ ) (containing $0.94 \mathrm{mmol}$ of $\mathrm{Cl}$ per gram of resin) and the non-anchored unsymmetrical Schiff base, $\mathrm{L}^{\prime} \mathrm{H}_{3}$ (obtained by the condensation of 3-formylsalicylic acid, ethylenediamine and acetylacetone) in DMF in presence of ethyl acetate (EA) and triethyamine (TEA). For the syntheses of $\mathbf{I}$ and II, $\mathrm{PSCH}_{2}-\mathrm{NH}_{2}$ or $\mathrm{PSCH}_{2}-\mathrm{Cl}$ crosslinked with $1 \%$ divinylbenzene was selected, because higher crosslinking affects the metal-adsorbing power of $\mathbf{I}$ and II. The formation of I and II may be shown as in scheme 1 .

$\mathrm{PSCH}_{2}-\mathrm{NH}_{2}$ is cream-coloured, while 2-hydroxyacetanilide is white. As the reaction between these takes place in DMF, cream-coloured polystyreneanchored Schiff base, $\mathrm{PSCH}_{2}-\mathrm{LH}$ (I) is obtained. On the other hand, $\mathrm{PSCH}_{2}-\mathrm{Cl}$ is white, $\mathrm{L}^{\prime} \mathrm{H}_{3}$ is yellow. As the reaction between $\mathrm{PSCH}_{2}-\mathrm{Cl}$ and $\mathrm{L}^{\prime} \mathrm{H}_{3}$ in DMF in presence of ethyl acetate and triethylamine takes place, yellow-coloured $\mathrm{PSCH}_{2}-\mathrm{LH}_{2}$ (II) is obtained. The colours of I or II remain the same even after prolonged washings with DMF, $\mathrm{CH}_{3} \mathrm{OH}$, $\mathrm{C}_{2} \mathrm{H}_{5} \mathrm{OH}$, acetone etc. It is worth mentioning that $\mathbf{I}$ or II are synthesized by refluxing $\mathrm{PSCH}_{2}-\mathrm{NH}_{2}$ : 2- 
hydroxyacetanilide or $\mathrm{PSCH}_{2}-\mathrm{Cl}: \mathrm{L}^{\prime} \mathrm{H}_{3}$ in $1: 3$ molar ratio for $8 \mathrm{~h}$. If the time is less than $8 \mathrm{~h}$ and the ratio $1:<3$, I or II always contain some unreacted $-\mathrm{CH}_{2}-\mathrm{NH}_{2}$ or $-\mathrm{CH}_{2}-\mathrm{Cl}$ group respectively. I and II are insoluble in aqueous and non-aqueous solvents. However, they undergo considerable swelling in DMF. In the present study, DMF was chosen as solvent due to its high dielectric constant and its ability to dissolve a large number of metal salts/metal complexes. Elemental analysis suggests $100 \%$ conversion of $\mathrm{PSCH}_{2}-\mathrm{NH}_{2}$ or $\mathrm{PSCH}_{2}-\mathrm{Cl}$ to I or II respectively. Polystyrene-anchored coordination compounds are synthesized by the reaction of I or II with metal salts/metal complexes in $1: 2$ molar ratio. As the above reaction proceeds, the cream colour of I or yellow colour of II changes to yellow, light brown, brown, reddish brown, yellowish green or orange yellow. The colours of polystyrene-anchored coordination compounds remain unchanged even after several washings with $\mathrm{DMF}, \mathrm{CH}_{3} \mathrm{OH}, \mathrm{C}_{2} \mathrm{H}_{5} \mathrm{OH}$ and petroleum ether. The compounds are insoluble in water as well as in other organic solvents. The analytical data show that polystyrene-anchored coordination compounds of $\mathbf{I}$ have the compositions: $\mathrm{PSCH}_{2}-\mathrm{LMoO}_{2}(\mathrm{acac}), \mathrm{PSCH}_{2}-\mathrm{LM}\left(\mathrm{CH}_{3} \mathrm{COO}\right) \cdot \mathrm{DMF}$ (where $\mathrm{M}=\mathrm{Co}, \mathrm{Cu}, \mathrm{Zn}, \mathrm{Cd}, \mathrm{UO}_{2}$ ), $\mathrm{PSCH}_{2}-$ $\mathrm{LFeCl}_{2} \cdot 2 \mathrm{DMF}$ and $\mathrm{PSCH}_{2}-\mathrm{LNi}\left(\mathrm{CH}_{3} \mathrm{COO}\right) \cdot 3 \mathrm{DMF}$. On the other hand, polystyrene-anchored coordination compounds of II have the compositions: $\mathrm{PSCH}_{2}-\mathrm{L}^{\prime} \mathrm{M}$ (where $\mathrm{M}=\mathrm{Co}, \mathrm{Ni}, \mathrm{Cu}, \mathrm{Zn}, \mathrm{Cd}, \mathrm{MoO}_{2}$, $\left.\mathrm{UO}_{2}\right), \quad \mathrm{PSCH}_{2}-\mathrm{L}^{\prime} \mathrm{FeCl} \cdot \mathrm{DMF}, \quad \mathrm{PSCH}_{2}-\mathrm{L}^{\prime} \mathrm{Mn} \cdot 2 \mathrm{DMF}$ and $\mathrm{PSCH}_{2}-\mathrm{L}^{\prime} \mathrm{Zr}(\mathrm{OH})_{2}$. DMF. DMF molecules coordinated with these compounds are lost completely on heating to a definite temperature in an oven. The per cent reaction conversions of $\mathbf{I}$ and II to produce polystyrene-supported coordination compounds lie between 34.6 and 91.4 and 39.4 and 93.5 respectively (table 1). There is no apparent correlation between per cent reaction conversion and the size of the metal ions. The metal-binding capacity of $\mathrm{PSCH}_{2}-\mathrm{LH}$ and $\mathrm{PSCH}_{2}-\mathrm{L}^{\prime} \mathrm{H}_{2}$ is in the range: 0.531.31 and $0.27-0.68 \mathrm{mmol}$ of metal per gram of $\mathbf{I}$ and II respectively (table 1 ).

\subsection{IR spectra}

IR spectra of the non-anchored Schiff base $\left(\mathrm{L}^{\prime} \mathrm{H}_{3}\right)$, polystyrene-anchored Schiff bases (I and II) and the coordination compounds of $\mathbf{I}$ and II were recorded in $\mathrm{KBr}$. $\mathrm{PSCH}_{2}-\mathrm{LH}, \mathrm{L}^{\prime} \mathrm{H}_{3}$ and $\mathrm{PSCH}_{2}-\mathrm{L}^{\prime} \mathrm{H}_{2}$ exhibit a strong band at $\sim 3250 \mathrm{~cm}^{-1}$ due to intramolecular hy- drogen-bonded phenolic and/or enolic $\mathrm{OH}$ groups. ${ }^{15}$ Polystyrene-anchored coordination compounds of $\mathbf{I}$ and II, other than $\mathrm{PSCH}_{2}-\mathrm{L}^{\prime} \mathrm{Zr}(\mathrm{OH})_{2} \cdot \mathrm{DMF}$, do not exhibit this band. The disappearance of this band upon complexation indicates the breakdown of hydrogen bonding followed by deprotonation of the phenolic and/or enolic $\mathrm{OH}$ groups and the subsequent involvement of phenolic and enolic oxygen atoms in the coordination. ${ }^{15} \mathrm{PSCH}_{2}-\mathrm{L}^{\prime} \mathrm{Zr}(\mathrm{OH})_{2}$. DMF exhibits the above band at $\sim 3400 \mathrm{~cm}^{-1}$ indicating the presence of coordinated $\mathrm{OH}$ groups. ${ }^{16}$ In the polystyrene-anchored coordination compounds of the metal ions with low PRCs, one expects retention of the band in the vicinity of $3250 \mathrm{~cm}^{-1}$, however, we were unable to locate this band in our compounds. The $v(\mathrm{C}=\mathrm{O})$ (carboxylic) stretch ${ }^{15}$ in 3 -formylsalicylic acid occurs at $1660 \mathrm{~cm}^{-1}$. The appearance of a new band at $1730 \mathrm{~cm}^{-1}$ due to $v(\mathrm{C}=\mathrm{O})$ (ester) in $\mathrm{PSCH}_{2}-\mathrm{L}^{\prime} \mathrm{H}_{2}$ confirms the covalent bond formation via the ester linkage ${ }^{15}$ between $\mathrm{L}^{\prime} \mathrm{H}_{3}$ and $\mathrm{PSCH}_{2}-\mathrm{Cl}$. This band remains unchanged in the polystyreneanchored coordination compounds, indicating the non-participation of ester oxygen atoms in coordination. II occurs in keto form as evident by the appearance of a strong band at $1725 \mathrm{~cm}^{-1}$ due to $v(\mathrm{C}=\mathrm{O})$ (keto) stretch. ${ }^{17}$ Polystyrene-anchored coordination compounds do not exhibit this band but exhibit a new band at $1670-1680 \mathrm{~cm}^{-1}$. The disappearence of the $v(\mathrm{C}=\mathrm{O})$ (keto) band in II and the appearance of a new band in its corresponding coordination compounds indicates keto-enol tautomerism followed by subsequent deprotonation of the enolic hydrogen atom and coordination to the concerned central metal ion. ${ }^{17}$ The $\mathrm{v}(\mathrm{C}=\mathrm{N})$ (azomethine) and $\mathrm{v}(\mathrm{C}-\mathrm{O})$ (phenolic) stretches in $\mathrm{PSCH}_{2}-\mathrm{LH}, \mathrm{L}^{\prime} \mathrm{H}_{3}$ and $\mathrm{PSCH}_{2}-$ $\mathrm{L}^{\prime} \mathrm{H}_{2}$ occur at $1635,1640,1640 \mathrm{~cm}^{-1}$ and 1515,1525 , $1525 \mathrm{~cm}^{-1}$ respectively. In polystyrene-anchored coordination compounds, $v(\mathrm{C}=\mathrm{N})$ (azomethine) stretch undergoes a negative shift by $10-35 \mathrm{~cm}^{-1}$ indicating coordination of the azomethene nitrogen atom to the metal ions. ${ }^{15}$ The $v(\mathrm{C}-\mathrm{O})$ (phenolic) band shifts in the complexes to higher energy by $\leq 10 \mathrm{~cm}^{-1}$ indicating the coordination of the phenolic oxygen atom. ${ }^{15}$ The data rule out the presence of a dimetallic structure and indicate a monometallic structure as in the case of a dimetallic structure, the $\mathrm{v}(\mathrm{C}-\mathrm{O})$ (phenolic) stretch is expected to undergo a positive shift ${ }^{18}$ by $>10 \mathrm{~cm}^{-1}$. The shifts in the IR frequencies after coordination with metal ions indicate the bidentate $\mathrm{ON}$ donor behaviour of $\mathrm{PSCH}_{2}-\mathrm{LH}$ and tetradentate ONNO donor behaviour of $\mathrm{PSCH}_{2}-\mathrm{L}^{\prime} \mathrm{H}_{2}$. 
Table 1. Colour, analytical and other characterization data of polystyrene-anchored compounds ${ }^{\mathrm{a}}$.

\begin{tabular}{|c|c|c|c|c|c|}
\hline \multirow{2}{*}{$\begin{array}{l}\text { Polystyrene-anchored } \\
\text { coordination compounds }\end{array}$} & \multirow[b]{2}{*}{ Colour } & \multicolumn{2}{|c|}{ Found (calcd) (\%) } & \multirow{2}{*}{$\begin{array}{l}\text { Metal binding } \\
\text { capacity }(\mathrm{mmol} / \mathrm{g} \\
\text { of resin) }\end{array}$} & \multirow{2}{*}{$\begin{array}{l}\text { Percent } \\
\text { reaction } \\
\text { conversion }\end{array}$} \\
\hline & & M & DMF & & \\
\hline $\mathrm{PSCH}_{2}-\mathrm{LMoO}_{2}$ (acac) & Yellow & $12 \cdot 6(13 \cdot 78)$ & - & $1 \cdot 31$ & $91 \cdot 4$ \\
\hline $\mathrm{PSCH}_{2}-\mathrm{LCo}\left(\mathrm{CH}_{3} \mathrm{COO}\right) \cdot \mathrm{DMF}$ & Light brown & $3 \cdot 1(8 \cdot 96)$ & $3 \cdot 7(11 \cdot 11)$ & 0.53 & $34 \cdot 6$ \\
\hline $\mathrm{PSCH}_{2}-\mathrm{LCu}\left(\mathrm{CH}_{3} \mathrm{COO}\right) \cdot \mathrm{DMF}$ & Light brown & $7 \cdot 1(9 \cdot 60)$ & $7 \cdot 9(11 \cdot 03)$ & $1 \cdot 12$ & $74 \cdot 0$ \\
\hline $\mathrm{PSCH}_{2}-\mathrm{LZn}\left(\mathrm{CH}_{3} \mathrm{COO}\right) \cdot \mathrm{DMF}$ & Cream & $5 \cdot 1(9 \cdot 85)$ & $5 \cdot 8(11 \cdot 00)$ & 0.78 & $51 \cdot 8$ \\
\hline $\mathrm{PSCH}_{2}-\mathrm{LCd}\left(\mathrm{CH}_{3} \mathrm{COO}\right) \cdot \mathrm{DMF}$ & Cream & $11 \cdot 6(15 \cdot 81)$ & $7 \cdot 3(10 \cdot 27)$ & $1 \cdot 03$ & $73 \cdot 4$ \\
\hline $\mathrm{PSCH}_{2}-\mathrm{LUO}_{2}\left(\mathrm{CH}_{3} \mathrm{COO}\right) \cdot \mathrm{DMF}$ & Yellow & $16 \cdot 2(27 \cdot 41)$ & $5 \cdot 2(8 \cdot 41)$ & 0.68 & $59 \cdot 1$ \\
\hline $\mathrm{PSCH}_{2}-\mathrm{LFeCl}_{2} \cdot 2 \mathrm{DMF}$ & Brown & $5 \cdot 7(7 \cdot 56)$ & $15 \cdot 1(19 \cdot 75)$ & $1 \cdot 02$ & $75 \cdot 4$ \\
\hline $\mathrm{PSCH}_{2}-\mathrm{LNi}\left(\mathrm{CH}_{3} \mathrm{COO}\right) \cdot 3 \mathrm{DMF}$ & Yellow green & $5 \cdot 8(7 \cdot 31)$ & $21 \cdot 4(27 \cdot 27)$ & 0.99 & $79 \cdot 3$ \\
\hline $\mathrm{PSCH}_{2}-\mathrm{L}^{\prime} \mathrm{MoO}_{2}$ & Yellowish brown & $2 \cdot 6(6 \cdot 60)$ & - & $0 \cdot 27$ & $39 \cdot 4$ \\
\hline $\mathrm{PSCH}_{2}-\mathrm{L}^{\prime} \mathrm{Co}$ & Brown & $4 \cdot 0(4 \cdot 28)$ & - & 0.68 & $93 \cdot 5$ \\
\hline $\mathrm{PSCH}_{2}-\mathrm{L}^{\prime} \mathrm{Cu}$ & Dark brown & $3 \cdot 7(4 \cdot 60)$ & - & $0 \cdot 58$ & $80 \cdot 4$ \\
\hline $\mathrm{PSCH}_{2}-\mathrm{L}^{\prime} \mathrm{Zn}$ & Light yellow & $3 \cdot 0(4 \cdot 72)$ & - & 0.46 & $63 \cdot 6$ \\
\hline $\mathrm{PSCH}_{2}-\mathrm{L}^{\prime} \mathrm{Cd}$ & Light yellow & $6 \cdot 4(7 \cdot 86)$ & - & $0 \cdot 57$ & $81 \cdot 4$ \\
\hline $\mathrm{PSCH}_{2}-\mathrm{L}^{\prime} \mathrm{Ni}$ & Yellowish green & $3 \cdot 9(4 \cdot 23)$ & - & 0.67 & $92 \cdot 2$ \\
\hline $\mathrm{PSCH}_{2}-\mathrm{L}^{\prime} \mathrm{UO}_{2}$ & Yellowish orange & $12 \cdot 5(15 \cdot 74)$ & - & $0 \cdot 52$ & $79 \cdot 4$ \\
\hline $\mathrm{PSCH}_{2}-\mathrm{L}^{\prime} \mathrm{FeCl} \cdot \mathrm{DMF}$ & Reddish brown & $1 \cdot 9(3 \cdot 86)$ & $1 \cdot 3(2 \cdot 49)$ & $0 \cdot 34$ & $49 \cdot 2$ \\
\hline $\mathrm{PSCH}_{2}-\mathrm{L}^{\prime} \mathrm{Zr}(\mathrm{OH})_{2} \cdot \mathrm{DMF}$ & Cream & $3 \cdot 3(6 \cdot 02)$ & $2 \cdot 7(4 \cdot 82)$ & $0 \cdot 36$ & $54 \cdot 8$ \\
\hline $\mathrm{PSCH}_{2}-\mathrm{L}^{\prime} \mathrm{Mn} \cdot 2 \mathrm{DMF}$ & Dark brown & $1 \cdot 8(3 \cdot 62)$ & $4 \cdot 8(9 \cdot 60)$ & $0 \cdot 33$ & $49 \cdot 7$ \\
\hline
\end{tabular}

a Abbreviations: $\mathrm{PSCH}_{2}-\mathrm{LH}=\mathbf{I}, \mathrm{PSCH}_{2}-\mathrm{L}^{\prime} \mathrm{H}_{2}=\mathbf{I I}, \mathrm{DMF}=$ dimethylformamide

The $v_{\text {asy }}(\mathrm{COO})$ and $\mathrm{v}_{\text {sy }}(\mathrm{COO})$ stretches of free acetate ions occur at 1560 and $1416 \mathrm{~cm}^{-1}$ respectively. ${ }^{19}$ The $v_{\text {asy }}(\mathrm{COO})$ and $\mathrm{v}_{\mathrm{sy}}(\mathrm{COO})$ in polystyrene-anchored metal acetate complexes occur in the range of $1590-1595$ and $1355-1385 \mathrm{~cm}^{-1}$ respectively. The energy separation $\left(205-240 \mathrm{~cm}^{-1}\right)$ between $v_{\text {asy }}(\mathrm{COO})$ and $v_{\text {sy }}(\mathrm{COO})$ is $>144 \mathrm{~cm}^{-1}$ and this indicates the monodentate nature of the acetate ion, since in the event of bidentate coordination, the energy separation ${ }^{20}$ is $<144 \mathrm{~cm}^{-1}$. DMF shows a band at $1680 \mathrm{~cm}^{-1}$ due to the $v(\mathrm{C}=\mathrm{O})$ stretch. ${ }^{15}$ This band shifts to lower energy by $10-40 \mathrm{~cm}^{-1}$ in the complexes indicating ${ }^{15}$ the oxygen coordination of DMF. $\mathrm{PSCH}_{2}-\mathrm{LMoO}_{2}$ (acac) and $\mathrm{PSCH}_{2}-\mathrm{L}^{\prime} \mathrm{MoO}_{2}$ exhibit $\mathrm{v}_{\mathrm{sy}}(\mathrm{O}=\mathrm{Mo}=\mathrm{O})$ stretches at 935 and $940 \mathrm{~cm}^{-1}$ and $\mathrm{v}_{\text {asy }}(\mathrm{O}=\mathrm{Mo}=\mathrm{O})$ stretches at 905 and $900 \mathrm{~cm}^{-1}$ respectively. These bands occur in the usual ranges $\left(892-964 \mathrm{~cm}^{-1}\right)$, $\left(840-925 \mathrm{~cm}^{-1}\right)$ reported for the majority of $\mathrm{MoO}_{2}(\mathrm{VI})$ compounds. $^{21}$ The presence of both $\mathrm{v}_{\mathrm{sy}}(\mathrm{O}=\mathrm{Mo}=\mathrm{O})$ and $\mathrm{v}_{\mathrm{asy}}(\mathrm{O}=\mathrm{Mo}=\mathrm{O})$ bands in the present compounds suggests a cis- $\mathrm{MoO}_{2}$ structure, because a dioxomolybdenum(VI) compound having a trans $-\mathrm{MoO}_{2}$ structure is expected to exhibit only the $\mathrm{v}_{\text {asy }}(\mathrm{O}=\mathrm{Mo}=\mathrm{O})$ band since $\mathrm{v}_{\mathrm{sy}}(\mathrm{O}=\mathrm{Mo}=\mathrm{O})$ band is IR inactive. The present dioxomolybdenum(VI) compounds do not have any band at $\sim 770 \mathrm{~cm}^{-1}$ indicating the absence of an oligomeric chain structure ${ }^{21}$ $\cdots \mathrm{Mo}=\mathrm{O} \cdots \mathrm{Mo}=\mathrm{O} \cdots . \mathrm{PSCH}_{2}-\mathrm{LUO}_{2}\left(\mathrm{CH}_{3} \mathrm{COO}\right) \cdot \mathrm{DMF}$ and $\mathrm{PSCH}_{2}-\mathrm{L}^{\prime} \mathrm{UO}_{2}$ show the $\mathrm{v}_{\text {asy }}(\mathrm{O}=\mathrm{U}=\mathrm{O})$ stretch at 910 and $895 \mathrm{~cm}^{-1}$ respectively. This band occurs in the usual range $\left(870-950 \mathrm{~cm}^{-1}\right)$ observed for the majority of trans- $\mathrm{UO}_{2}$ compounds. ${ }^{22}$ The force constants $\left(\mathrm{f}_{\mathrm{U}-\mathrm{O}}\right)$ and the $\mathrm{U}-\mathrm{O}$ bond lengths in these compounds are about $6.66-6.88 \mathrm{mdyn} / \AA$ and $1.74 \AA$ respectively. These values are in the reported range $(6 \cdot 58-$ $7.03 \mathrm{mdyn} / \AA$ and $1.60-1.92 \AA$ ) observed for the majority of dioxouranium(VI) compounds. ${ }^{23}$ Polystyrene-anchored iron(III) compounds do not exhibit any new band at $820-860 \mathrm{~cm}^{-1}$ due to $v_{\text {sy }}(\mathrm{Fe}-\mathrm{O}-\mathrm{Fe})$ stretch and this precludes the presence of any oxobridged structures in these compounds. ${ }^{24}$ Such oxobridge formation is not possible in the present compounds due to the long distances between adjacent iron centres. The absence of a band between 850$950 \mathrm{~cm}^{-1}$, characteristic of $\mathrm{v}(\mathrm{Zr}=\mathrm{O}) \operatorname{stretch}^{25}$ in polystyrene-anchored zirconium(IV) coordinaton compounds, suggests that its structure is $\mathrm{PSCH}_{2}-$ $\mathrm{L}^{\prime} \mathrm{Zr}(\mathrm{OH})_{2} \cdot \mathrm{DMF}$ and not $\mathrm{PSCH}_{2}-\mathrm{L}^{\prime} \mathrm{ZrO} \cdot \mathrm{H}_{2} \mathrm{O} \cdot \mathrm{DMF}$. The appearance of a band at $1130 \mathrm{~cm}^{-1}$ due to $\delta(\mathrm{Zr}-$ $\mathrm{OH})$ also supports the suggested structure of the complex. $^{15,16}$

\subsection{Reflectance spectra}

Polystyrene-anchored coordination compounds are insoluble in common organic solvents. They also do 
not form good mull with nujol. Hence, their solution spectra or nujol mull spectra could not be recorded. $\mathrm{PSCH}_{2}-\mathrm{LCo}\left(\mathrm{CH}_{3} \mathrm{COO}\right)$. DMF and $\mathrm{PSCH}_{2}-\mathrm{L}^{\prime} \mathrm{Co}$ exhibit two bands, the first at $8400,8750 \mathrm{~cm}^{-1}$ and the second at $\sim 25000 \mathrm{~cm}^{-1}$, corresponding to ${ }^{1} A_{1 g} \rightarrow$ ${ }^{1} B_{2 g}$ and ${ }^{1} A_{1 g} \rightarrow{ }^{1} B_{1 g}$ transitions respectively, indicating square planar symmetry. ${ }^{15} \mathrm{PSCH}_{2}-\mathrm{LNi}$ $\left(\mathrm{CH}_{3} \mathrm{COO}\right) \cdot 3 \mathrm{DMF}$ exhibits two bands at 9000 and $15500 \mathrm{~cm}^{-1}$ corresponding to ${ }^{3} A_{2 g} \rightarrow{ }^{3} T_{2 g}\left(v_{1}\right)$ and ${ }^{3} A_{2 g} \rightarrow{ }^{3} T_{1 g}(F)\left(v_{2}\right)$ transitions respectively, indicating octahedral symmetry. ${ }^{15}$ Another band at $25500 \mathrm{~cm}^{-1}$ corresponding to ${ }^{3} A_{2 g} \rightarrow{ }^{3} T_{1 g}(P)\left(v_{3}\right)$ transition could not be located as it merges with the strong chargetransfer band. The $v_{2}: v_{1}$ value for the present compound is 1.72 which lies within the usual range (1.60-1.82) observed for the majority of octahedral $\mathrm{Ni}(\mathrm{II})$ compounds. ${ }^{26} \mathrm{PSCH}_{2}-\mathrm{L}^{\prime} \mathrm{Ni}$ exhibits two bands at 20000 and $24000 \mathrm{~cm}^{-1}$ due to the ${ }^{1} A_{1 g} \rightarrow$ ${ }^{1} A_{2 g}\left(\mathrm{v}_{2}\right)$ and ${ }^{1} A_{1 g} \rightarrow{ }^{1} B_{2 g}\left(\mathrm{v}_{3}\right)$ transitions in square planar geometry. ${ }^{15}$ It also exhibits a weak band at $12450 \mathrm{~cm}^{-1}$ which is assigned to a spin-forbidden ${ }^{1} A_{1 g} \rightarrow{ }^{3} A_{2 g}\left(v_{1}\right)$ transition. $\mathrm{PSCH}_{2}-\mathrm{LCu}\left(\mathrm{CH}_{3} \cdot \mathrm{COO}\right)$. DMF and $\mathrm{PSCH}_{2}-\mathrm{L}^{\prime} \mathrm{Cu}$ exhibit a broad band at 18600 and $18350 \mathrm{~cm}^{-1}$ due to the ${ }^{2} B_{1 g} \rightarrow{ }^{2} A_{1 g},{ }^{2} B_{2 g}$ and ${ }^{2} E_{g}$ transitions, characteristic of square planar symmetry. ${ }^{27} \mathrm{PSCH}_{2}-\mathrm{LFeCl}_{2} \cdot 2 \mathrm{DMF}$ and $\mathrm{PSCH}_{2}-$ $\mathrm{L}^{\prime} \mathrm{FeCl} \cdot \mathrm{DMF}$ show three bands; first at 12200 , $12650 \mathrm{~cm}^{-1}$, second at $15500(\mathrm{sh}), 16970 \mathrm{~cm}^{-1}$ and third at $19000,25000 \mathrm{~cm}^{-1}$ respectively, corresponding to ${ }^{6} A_{1 g} \rightarrow{ }^{4} T_{1 g}(G),{ }^{6} A_{1 g} \rightarrow{ }^{4} T_{2 g}(G)$, and ${ }^{6} A_{1 g} \rightarrow$ ${ }^{4} A_{1 g}(G)$ transitions respectively, in octahedral symmetry. ${ }^{15} \mathrm{PSCH}_{2}-\mathrm{L}^{\prime} \mathrm{Mn} \cdot 2 \mathrm{DMF}$ exhibits two bands at 16950 and $24400 \mathrm{~cm}^{-1}$ due to ${ }^{6} A_{1 g} \rightarrow{ }^{4} T_{2 g}(G)$ and ${ }^{6} A_{1 g} \rightarrow{ }^{4} A_{1 g}(G)$ transitions respectively, in octahedral symmetry. ${ }^{15}$

\subsection{ESR spectra}

ESR spectra of $\mathrm{PSCH}_{2}-\mathrm{L}^{\prime} \mathrm{Cu}$ exhibit two $g$ values $\left(g_{\|}=2.26\right.$ and $\left.g_{\perp}=2.09\right)$ indicating the presence of tetragonal-type symmetry about the $\mathrm{Cu}(\mathrm{II})$ ion. ${ }^{15}$ The parameters of the present $\mathrm{Cu}$ (II) compound are: $A_{\|}=1.52 \times 10^{-2} \mathrm{~cm}^{-1}, A_{\perp}=3.0 \times 10^{-3} \mathrm{~cm}^{-1} \quad G=2.9$, $\alpha_{\mathrm{Cn}}^{2}=0.76, \quad\left(\alpha^{\prime}\right)^{2}=0.32, \kappa=0.49$ and $P_{d}=1.56 \times$ $10^{-2} \mathrm{~cm}^{-1}$. The data indicate that $g_{\|}>g_{\perp}$ and $A_{\|}>A_{\perp}$ which are indicative of the presence of the unpaired electron in the $d_{x^{2}-y^{2}}$ orbital. ${ }^{15}$ The higher value of $g_{\|}$ is due to greater elongation in the $z$-axis of the compound with ${ }^{2} B_{1 g}$ ground state. The $g_{\|}$value $(2 \cdot 26)$ indicates that the metal-ligand bonding in the compound is covalent. The $G$ value (2.9) indicates the strong field nature of $\mathrm{PSCH}_{2}-\mathrm{L}^{\prime} \mathrm{H}_{2}$. The values of $\alpha_{\mathrm{Cn}}^{2}(0.76)$ and $\left(\alpha^{\prime}\right)^{2}(0.32)$ indicate the covalent nature of $\mathrm{PSCH}_{2}-\mathrm{L}^{\prime} \mathrm{Cu}$. The values of $k$ and $P_{d}$ are 0.49 and $1.56 \times 10^{-2} \mathrm{~cm}^{-1}$ respectively. The positive value of $k$ suggests ${ }^{15}$ that $A_{\|}$should be greater than $A_{\perp}$ and this trend in $A_{\|}$and $A_{\perp}$ values has also been observed by us. The lower value of $P_{d}\left(1.56 \times 10^{-2}\right.$ $\mathrm{cm}^{-1}$ ) in the present compound in comparison to the free ion value $\left(3.5 \times 10^{-2} \mathrm{~cm}^{-1}\right)$ indicates the presence of the covalent character in the metal-ligand bonding. The absence of $\Delta M s=2$ transitions (1500 gauss) indicates that there is no $\mathrm{Cu}-\mathrm{Cu}$ interaction in the present compound. The metal ions on the phenyl ring of $\mathrm{PSCH}_{2}-\mathrm{Cl}$ are situated eight to nine styrene units apart when the percent reaction conversion is 100 and more than nine when the percent reaction conversion is $<100$. This leads to a magnetically dilute environment around the metal ions, since the pathway for $\mathrm{M}-\mathrm{M}$ interaction is blocked. However, as $\mathrm{PSCH}_{2}-\mathrm{Cl}$ is $1 \%$ crosslinked with divinylbenzene, the polymer chains are twisted and overlapping and this may bring some reactive groups closer, as a result of which some M-M interaction takes place that is not detected by ESR measurements.

\subsection{Magnetic susceptibility measurements}

$\mathrm{PSCH}_{2}-\mathrm{LCo}\left(\mathrm{CH}_{3} \mathrm{COO}\right)$. DMF and $\mathrm{PSCH}_{2}-\mathrm{L}^{\prime} \mathrm{Co}$ exhibit magnetic moments 2.40 and $2.65 \mathrm{BM}$ respectively. These values are within the normal range (2.20-2.70 BM), reported for square planar geometry. ${ }^{28}$ $\mathrm{PSCH}_{2}-\mathrm{LCu}\left(\mathrm{CH}_{3} \mathrm{COO}\right)$. DMF and $\mathrm{PSCH}_{2}-\mathrm{L}^{\prime} \mathrm{Cu}$ exhibit magnetic moments of 1.85 and $1.93 \mathrm{BM}$ respectively, which are close to the range (1.75$2 \cdot 20 \mathrm{BM})$, expected for magnetically dilute $\mathrm{Cu}(\mathrm{II})$ compounds. ${ }^{26} \mathrm{PSCH}_{2}-\mathrm{LNi}\left(\mathrm{CH}_{3} \mathrm{COO}\right) \cdot 3 \mathrm{DMF}$ exhibits a magnetic moment of $2.93 \mathrm{BM}$ which is within the normal range expected for magnetically dilute octahedral Ni(II) compounds. ${ }^{28}$ The magnetic moments of $\mathrm{PSCH}_{2}-\mathrm{LFeCl}_{2} \cdot 2 \mathrm{DMF}, \mathrm{PSCH}_{2}-\mathrm{L}^{\prime} \mathrm{FeCl}$. DMF and $\mathrm{PSCH}_{2}-\mathrm{L}^{\prime} \mathrm{Mn} \cdot 2 \mathrm{DMF}$ are 6.00, 5.94 and $5.92 \mathrm{BM}$ respectively which are close to the expected value (5.92 BM) for octahedral geometry. ${ }^{28}$

\section{Conclusion}

Magnetically dilute square planar compounds, $\mathrm{PSCH}_{2}-\mathrm{LM}\left(\mathrm{CH}_{3} \mathrm{COO}\right) \cdot \mathrm{DMF} \quad(\mathrm{M}=\mathrm{Co}, \mathrm{Cu})$ and $\mathrm{PSCH}_{2}-\mathrm{L}^{\prime} \mathrm{M}(\mathrm{M}=\mathrm{Co}, \mathrm{Ni}, \mathrm{Cu})$; tetrahedral compounds, $\mathrm{PSCH}_{2}-\mathrm{LM}\left(\mathrm{CH}_{3} \mathrm{COO}\right) \cdot \mathrm{DMF}(\mathrm{M}=\mathrm{Zn}, \mathrm{Cd})$ 
and $\mathrm{PSCH}_{2}-\mathrm{L}^{\prime} \mathrm{M}(\mathrm{M}=\mathrm{Zn}, \mathrm{Cd})$; octahedral compounds, $\mathrm{PSCH}_{2}-\mathrm{LMoO}_{2}$ (acac), $\quad \mathrm{PSCH}_{2}-\mathrm{L}^{\prime} \mathrm{MoO}_{2}, \quad \mathrm{PSCH}_{2}-$ $\mathrm{LM}\left(\mathrm{CH}_{3} \mathrm{COO}\right) \cdot \mathrm{DMF} \quad\left(\mathrm{M}=\mathrm{Ni}, \quad \mathrm{UO}_{2}\right), \quad \mathrm{PSCH}_{2}-$ $\mathrm{LFeCl}_{2} \cdot 2 \mathrm{DMF}, \mathrm{PSCH}_{2}-\mathrm{L}^{\prime} \mathrm{FeCl} \cdot \mathrm{DMF}$ and $\mathrm{PSCH}_{2}-$ L'Mn-2DMF; pentagonal-bipyramidal compound, $\mathrm{PSCH}_{2}-\mathrm{L}^{\prime} \mathrm{Zr}(\mathrm{OH})_{2}$. DMF have been synthesized and characterized on the basis of elemental analysis, spectral (IR, reflectance, ESR) and magnetic susceptibility measurements.

\section{Acknowledgements}

PKG is indebted to the Council of Scientific and Industrial Research, New Delhi for a fellowship.

\section{References}

1. Ciardelli F, Altomare A, Conti G, Arribas G, Mendez B and Ismayel A 1994 Macromol. Sym. 80 29; Canali L, Cowan E, Deleuze H, Gibson C L and Sherrington D C 2000 J. Chem. Soc., Perkin Trans. I 132055

2. Reddy N P, Kantam M L and Choudary B M 1989 Indian J. Chem. B28 105; Shinichi I, Yoshiki S, Koichi I, Toshihiro M and Seiichi N $1990 \mathrm{~J}$. Org. Chem. 55 304; Roice M, Kumar K S and Pillai V N R 2000 Tetrahedron 56 3725; Arunan C and Pillai V N R 2000 Tetrahedron $\mathbf{5 6} 3005$

3. Assmann A, Bonifacic M. Briviba K and Sies H 2000 Free Radical Res. 32371

4. Hutchins M S and Chapman T K 1994 Tetrahedron Lett. 354055

5. Neckers D C, Thayer A L and Schaap A P $1975 J$. Am. Chem. Soc. 955820

6. Pesavento N, Biesuz R, Baffi F and Gencco C 1999 Anal. Chim. Acta 401265

7. Sherrington D C 2000 Stud. Surf. Sci. Catal. B130 1655

8. Akelah A and Sherrington D C 1981 Chem. Rev. 81 557
9. Hodge P and Waterhouse J 1983 J. Chem. Soc., Perkin Trans. I 102319

10. Reddy A R and Reddy K H 2003 Proc. Indian Acad. Sci. (Chem. Sci.) 115155

11. Topich J 1982 Inorg. Chem. 21 2079; Jain V K, Handa A, Sait S S, Srivastava P and Aggarwal Y K 2001 Anal. Chim. Acta 429237

12. Syamal A and Singh M M 1994 React. Funct. Polym. 2427

13. Drago R S, Gaul J, Zombeck A and Staub D K 1980 J. Am. Chem. Soc. 102 1033; Akelah A, Abbasi M M and Azad M K H 1986 Indian J. Chem. A25 923

14. Kumar D, Gupta P K and Syamal A 2002 Indian J. Chem. A41 2494

15. Kumar D, Syamal A and Singh A K 2003 Indian J. Chem. A42 280

16. Syamal A and Kumar D 1993 Indian J. Chem. A32 625

17. Syamal A and Kale K S 1980 Indian J. Chem. A19 225

18. Sinn E and Harris C M 1969 Coord. Chem. Rev. 4 998

19. Nakamoto K 1987 Infrared and Raman spectra of inorganic and coordination compounds, 3rd edn (New York: Wiley Interscience) pp. 232, 249

20. Colthup N B, Daly L H and Wiberley S E 1975 Introduction to infrared and Raman spectroscopy 2nd edn (London: Academic Press) pp. 284, 408

21. Syamal A and Maurya M R 1989 Coord. Chem. Rev. 95183

22. Alyea E C, Malek A and Kazi A I 1981 Transition Met. Chem. 6223

23. McGlynn S P, Smith J H and Neely W C $1961 J$. Chem. Phys. 35105

24. Howkin D J and Grifith W P 1966 J. Chem. Soc. A 472

25. Spasibenko T P and Goroshchenko Y G 1969 Russ. J. Inorg. Chem. 14758

26. Syamal A 1987 Chem. Educ. 433

27. Singh N K and Singh S B 2001 Indian J. Chem. A40 1070

28. Cotton F A and Wilkinson G 1985 Advanced inorganic chemistry 3rd edn (New Delhi: Wiley Eastern) pp. 867-916 